\title{
UTILIZAÇÃO DE BIORREATOR À MEMBRANA PARA TRATAMENTO DE EFLUENTES
}

\author{
Alexandre Giacobbo \\ Doutorando em Engenharia de Materiais no Laboratório de Corrosão, Proteção e Reciclagem \\ de Materiais - LACOR, pelo Programa de Pós-Graduação em Engenharia de Minas, \\ Metalúrgica e de Materiais - PPGE3M , na Universidade Federal do Rio Grande do Sul - \\ UFRGS. E-mail: Alexandre_giacobbo@yahoo.com.br \\ Guilherme Lahm Feron \\ Aluno de Engenharia Ambiental e Bolsista no LACOR/PPGE3M/UFRGS. E-mail: \\ guiferon@hotmail.com \\ Marco Antônio Siqueira Rodrigues \\ Prof. Doutor do Programa de Qualidade Ambiental do Centro Universitário Feevale. E-mail: \\ marcor@feevale.br \\ Andréa Moura Bernardes \\ Prof. Doutor da Escola de Engenharia, LACOR/PPGE3M/UFRGS. E-mail: amb@ufrgs.br \\ Alvaro Meneguzzi \\ Prof. Doutor da Escola de Engenharia, LACOR/PPGE3M/UFRGS. E-mail: \\ alvaro.meneguzzi@gmail.com
}

\section{RESUMO}

A operação de MBR com fluxos elevados é um dos principais problemas deste sistema de tratamento de efluentes. Para atingir tal finalidade é necessário o estudo e otimização dos parâmetros de operação. Este trabalho teve como objetivo testar a funcionalidade de um MBR no tratamento de um efluente sintético, bem como, por meio de metodologias de planejamento de experimentos, estudar dois parâmetros fundamentais para operação de MBR: PTM e concentração de SST no lodo ativado. Desta forma, selecionou-se 3 membranas novas (todas do mesmo lote de fabricação), efetuou-se a compactação das membranas e, posteriormente, variando a pressão $\left(0,3\right.$ a $\left.1,5 \mathrm{kgf} / \mathrm{cm}^{2}\right)$ foram feitas a permeabilidade à água e permeabilidade ao lodo ativado (concentrações de 5, 10 e $15 \mathrm{~g} / \mathrm{L}$ de SST). A partir dos resultados observados os dados foram tabulados e analisados através da ANOVA. O ajuste ótimo foi: lodo ativado com $10 \mathrm{~g} / \mathrm{L}$ de SST e PTM de $0,6 \mathrm{kgf} / \mathrm{cm}^{2}$. Além disso, também foram constatadas permeabilidades diferentes entre membranas do mesmo lote de fabricação. $\mathrm{O}$ tratamento do efluente sintético com o MBR apresentou elevada eficiência, obtendo reduções superiores a $95 \%$ para DQO e turbidez.

PALAVRAS-CHAVE: MBR, Microfiltração, Tratamento de Efluentes, Permeabilidade, ANOVA

\section{USE MEMBRANE BIOREACTOR FOR WASTEWATER TREATMENT}

\begin{abstract}
The operation of MBR with high flow is one of the main problems of this system of wastewater treatment. To achieve this purpose it is necessary to study and optimize the parameters of operation. This study aimed to test the functionality of an MBR in treating synthetic wastewater and, through methodologies of experimental design to study two key parameters for the operation of MBR: PTM and TSS concentrations in activated sludge. Thus,
\end{abstract}


were selected three new membranes (all from the same fabrication lot), it was made the compactation of the membranes and subsequently varying the pressure $\left(0.3\right.$ to $\left.1.5 \mathrm{kgf} / \mathrm{cm}^{2}\right)$ it was done water permeability and activated sludge permeability (concentrations of 5, 10 and $15 \mathrm{~g} / \mathrm{L} \mathrm{TSS}$ ). From the results observed dates were tabulated and analyzed by ANOVA. The fit was great with activated sludge $10 \mathrm{~g} / \mathrm{L}$ of TSS and TPM $0.6 \mathrm{kgf} / \mathrm{cm}^{2}$. Besides, it was also seen different permeability among membranes from the same fabrication lot. Treatment of synthetic wastewater with MBR showed high efficiency, achieving reductions of more than $95 \%$ for COD and turbidity.

KEY-WORDS: MBR, Microfiltration, Effluents Treatment, Permeability, ANOVA 


\section{UTILIZAÇÃO DE BIORREATOR À MEMBRANA PARA TRATAMENTO DE EFLUENTES}

\section{INTRODUÇÃO}

Atualmente, a população em geral tem direcionado sua atenção aos aspectos ambientais, dentre os quais, talvez o mais preocupante, seja os recursos hídricos. Problemas relacionados à falta de água já fazem parte do cotidiano de muitas pessoas. $\mathrm{O}$ comprometimento da disponibilidade de água é causado principalmente por usos inadequados, bem como pela deterioração de sua qualidade ocasionada principalmente pelo descarte de efluentes tratados inadequadamente ou simplesmente não-tratados (GIACOBBO et al., 2010). Assim, para atingir um desenvolvimento sustentável é necessário conduzir o crescimento sócio-econômico sem agredir os recursos naturais. Para tanto, torna-se necessário a adoção de medidas que visem o uso racional da água; a aplicação de tecnologias e processos que conduzam ao reuso de efluentes industriais e domésticos; garantir as reservas necessárias para os ecossistemas naturais, entre outras ações proativas para o combate ao desperdício da água (PROVENZI, 2005).

Em regiões com carência de água, a utilização de águas residuárias tratadas é uma alternativa para aumentar a disponibilidade de água. Esta é a tendência atual, pois considera o efluente tratado como um recurso hídrico a ser utilizado para diversos fins (VIANA, 2004). Com a reciclagem do efluente tratado para usos não potáveis (irrigação de jardins, lavagem de pisos, etc.), libera-se a água de melhor qualidade para usos mais nobres, como o abastecimento doméstico.

Dentro deste contexto se inserem as tecnologias avançadas de tratamento de efluentes, como os processos de separação por membranas (PSM), dentre as quais, uma que tem ganhado destaque é a de biorreator à membrana (MBR). Estes, por sua vez, são reatores biológicos com biomassa em suspensão onde a separação de sólidos se dá por microfiltração através de membranas com tamanho de poro variando de 0,1 a 0,4 $\mu \mathrm{m}$ (METCALF, et al., 2003). Segundo Provenzi (2005), MBR consiste na união de um tratamento biológico, normalmente lodos ativados, a um processo de separação por membranas de micro ou ultrafiltração. Desta forma, biorreator à membrana é um processo híbrido que combina um processo biológico, geralmente aeróbio, a um processo físico de filtração por membranas.

O MBR oferece inúmeras vantagens em relação às tecnologias atuais, de tal forma que o efluente tratado, ou seja, o permeado, possui qualidade elevada, pois apresenta ausência de contaminação fecal e de sólidos suspensos. Suas características são superiores, na maioria dos casos, àquelas obtidas por uma estação convencional de tratamento de efluentes (VIANA, 2004).

No entanto, os PSM apresentam fatores limitantes que prejudicam seu desempenho, podendose citar: fouling, polarização por concentração e compactação da membrana (MAESTRI, 2007; MENDRET, et al., 2009). Estes, por sua vez, podem agir separadamente ou em conjunto, prejudicando a eficiência do sistema. A operação econômica da tecnologia de membranas depende da capacidade de garantir um fluxo elevado na menor pressão de operação possível, por longos períodos de tempo (SCHNEIDER \& TSUTIYA, 2001).

Segundo Viana (2004), a compactação é um fenômeno físico que provoca queda no fluxo permeado devido à deformação mecânica da membrana, estando vinculada à pressão aplicada e às suas características estruturais. Portanto, a compactação da membrana deve ser realizada antes da filtração propriamente dita, para evitar que este fenômeno ocorra durante a operação 
e seja confundida com o fouling. Para compactar uma membrana é necessário utilizar uma pressão transmembrana (PTM) igual ou levemente superior à pressão de trabalho e deixar o sistema permeando água até atingir fluxo de permeado constante.

Por sua vez, a polarização por concentração caracteriza-se pelo aumento da concentração de soluto na interface membrana/solução, gerando a retrodifusão do soluto em direção ao seio da solução. Este fenômeno estabelece um perfil de concentração do soluto na região próxima à interface membrana/solução, dificultando a filtração (PROVENZI, 2005). O fouling, ao contrário da polarização por concentração, geralmente é de natureza irreversível e dependente do tempo. Este fenômeno, também conhecido como incrustação e colmatação, caracteriza-se pela deposição, adsorção e/ou acúmulo de partículas coloidais suspensas sobre a superfície ou no interior dos poros da membrana, incluindo interação química entre os solutos e a membrana (RÄDER, 2003).

A luz destes fatos, torna-se necessário estudar os fenômenos que provocam a queda no fluxo permeado, a fim de otimizar os parâmetros do processo, possibilitando uma operação mais eficiente. Para tal finalidade, faz-se necessário o planejamento adequado dos ensaios a serem realizados, aumentando a confiabilidade dos mesmos. Para preencher esta lacuna, faz-se um planejamento experimental de acordo com metodologias pré-estabelecidas. Segundo Ribeiro \& Caten (2000), metodologias de Projeto de Experimentos são fortemente fundamentadas em premissas estatísticas, destinadas a otimizar o planejamento, execução e análise de um experimento. Assim, o uso de Projeto de Experimentos permite que se estruture adequadamente a sequência de ensaios de forma a traduzir os objetivos preestabelecidos pelo pesquisador. Ademais, em termos de informação, a eficiência de experimentos adequadamente planejados é superior a qualquer outra sequência não estruturada de ensaios.

Uma importante metodologia de Projeto de Experimentos é a Análise de Variância (ANOVA). Esta técnica de análise de dados experimentais envolve medidas quantitativas, sendo amplamente utilizada em estudos de melhoria de qualidade, desenvolvimento e/ou aprimoramento de processos, bem como avaliação de novas técnicas e matérias-primas (LIMPSON et al., 1973). À medida que diversas fontes estão agindo simultaneamente sobre um conjunto de observações, a variância das observações é a soma das variâncias das fontes independentes. Portanto, a ANOVA permite analisar a variância total dentro de um experimento, sendo que esta divisão pode ser devido a cada fator principal, interações entre fatores e erro residual. Então, a significância de cada variância é devidamente testada (LIMPSON et al., 1973; MONTGOMERY, 2001).

O objetivo deste trabalho foi determinar os parâmetros de operação de um MBR em escala de bancada através de ensaios preliminares de microfiltração, utilizando metodologias de Projeto de Experimentos. E, a partir de tais resultados, escolher a melhor combinação de parâmetros (concentração e pressão de operação) a fim de testar a funcionalidade do MBR.

\section{METODOLOGIA}

\section{ENSAIOS PRELIMINARES}

Para o desenvolvimento deste trabalho, foi utilizada uma unidade experimental de microfiltração em escala de bancada (Figura 1), com membranas poliméricas simétricas, de éster de celulose (Millipore) e poro nominal de $0,22 \mu \mathrm{m}$. O módulo de membranas é do tipo placa plana, possui $55 \mathrm{~cm}^{2}$ de área útil e operado com fluxo tangencial. 


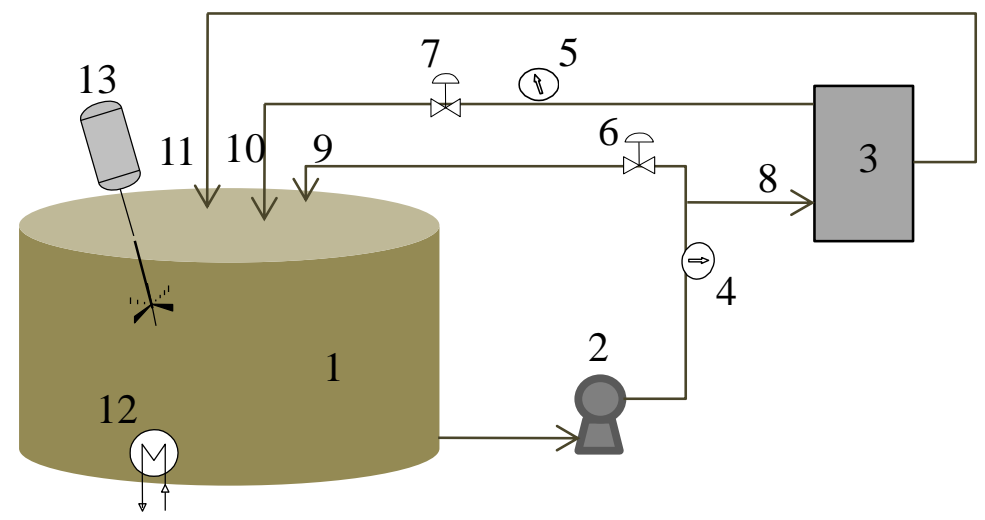

1-Reator; 2-Bomba de diafragma; 3-Módulo de membranas; 4-Manômetro 1; 5-Manômetro 2; 6-Válvula 1; 7-Válvula 2; 8-Corrente de alimentação; 9-Corrente de retorno; 10-Corrente de permeado; 11-Corrente de concentrado; 12-Trocador de calor; 13-Agitador mecânico.

Figura 1 - Unidade experimental de microfiltração.

Os ensaios foram realizados através de um sistema de microfiltração operado no modo de reciclo total, onde as correntes de permeado e concentrado retornavam ao reator. Desta forma, a concentração no reator pode ser considerada constante. A temperatura foi mantida constante em $22 \pm 1{ }^{\circ} \mathrm{C}$ e todos os ensaios foram conduzidos pelo mesmo operador. Além disso, o sistema foi conduzido em regime de mistura completa, com agitação constante, para evitar a sedimentação no reator do material suspenso.

Inicialmente, foram selecionadas 3 membranas do mesmo lote de fabricação. Antes de cada ensaio as membranas foram compactadas com água deionizada (condutividade de $0,01 \mathrm{mS}$ ) pelo período de 5 horas e PTM de $1,5 \mathrm{kgf} / \mathrm{cm}^{2}$.

Após a compactação, foi efetuado o teste de permeabilidade à água, utilizando-se água deionizada. Basicamente foi monitorado o fluxo de permeado, medindo-se o fluxo após cada 15 minutos operado em cada pressão, a qual foi variada em 5 níveis $\left(0,3\right.$ a $\left.1,5 \mathrm{kgf} / \mathrm{cm}^{2}\right)$. Devido à água ser livre de material em suspensão, sabe-se que ocorre um aumento linear do fluxo de permeado com o aumento da PTM. Estes ensaios foram realizados antes e após os testes de permeabilidade ao lodo ativado. Assim, pretende-se estimar a propensão da ocorrência ou não do fouling, bem como a variabilidade dentre as membranas do mesmo lote. Tomando a membrana como inerte ao solvente e incompressível pela ação da pressão, o fluxo de permeado de um solvente puro é diretamente proporcional à pressão transmembrana, para os processos que utilizam gradiente de pressão como força motriz (VIANA, 2004). Assim, determina-se a permeabilidade da membrana. Quando o solvente utilizado é água pura, este parâmetro é denominado permeabilidade hidráulica.

Onde:

$$
J_{p}=L_{p} \cdot \Delta P
$$

$\mathrm{J}_{\mathrm{p}}=$ Fluxo de permeado $\left[\mathrm{L} / \mathrm{m}^{2} . \mathrm{h}\right]$

$\mathrm{L}_{\mathrm{p}}=$ Permeabilidade da membrana para o solvente em questão $\left[\mathrm{L} / \mathrm{m}^{2}\right.$.h.bar $]$

$\Delta \mathrm{P}=$ Pressão transmembrana $[\mathrm{bar}]$

Na sequência, efetuou-se a permeabilidade ao lodo ativado, com 10 medidas de fluxo em cada pressão, uma a cada 3 minutos, também variando a pressão em 5 níveis $\left(0,3\right.$ a 1,5 kgf/ $\left.\mathrm{cm}^{2}\right)$, 
para avaliar a influência da concentração e PTM no fluxo de permeado. Ao final do experimento, os dados foram tabulados e devidamente analisados através da ANOVA.

Evidencia-se que os ensaios foram divididos em três blocos, executados um a cada dia e pelo mesmo operador. Cada bloco consiste na seguinte sequência: uma membrana, compactação, permeabilidade à água, permeabilidade ao lodo e novamente permeabilidade à água. Nas Tabelas 1 a 4 são listadas as variáveis de resposta, parâmetros do processo, fatores de ruído e fatores constantes, respectivamente.

Tabela 1: Variável de resposta

\begin{tabular}{l|c|c}
\hline Variável de Resposta & Tipo & Unidade \\
\hline Fluxo de Permeado & Maior-é-melhor & $\mathrm{L} / \mathrm{m}^{2} . \mathrm{h}$ \\
\hline
\end{tabular}

Tabela 2: Parâmetros do processo

\begin{tabular}{l|c}
\multicolumn{1}{c|}{ Parâmetros do processo } & Níveis \\
\hline Pressão Transmembrana $\left(\mathrm{kgf} / \mathrm{cm}^{2}\right)$ & 0,$3 ; 0,6 ; 0,9 ; 1,2 ; 1,5$ \\
\hline Membranas & $1 ; 2 ; 3$ \\
\hline Concentração do Lodo $(\mathrm{g} / \mathrm{L})$ & $5 ; 10 ; 15$ \\
\hline
\end{tabular}

Tabela 3: Fatores de ruído

\begin{tabular}{l}
\hline \multicolumn{1}{c}{ Fatores de ruído } \\
\hline Habilidade do operador \\
\hline Precisão nas medições dos ensaios \\
\hline
\end{tabular}

Tabela 4: Fatores constantes

\begin{tabular}{l|c}
\multicolumn{1}{c|}{ Fatores constantes } & Nível \\
\hline Temperatura & $22 \pm 1^{\circ} \mathrm{C}$ \\
\hline Operador & Único \\
\hline Agitação & $1000 \mathrm{rpm}$ \\
\hline Água deionizada & $0,01 \mathrm{mS}$ \\
\hline Aparato experimental & Único \\
\hline
\end{tabular}

\section{OPERAÇÃO DO MBR}

Após os ensaios preliminares, onde foram selecionados os parâmetros ótimos para a microfiltração do lodo ativado, foi realizada a montagem, operação e monitoramento do MBR.

A montagem do MBR foi realizada adicionando-se alguns equipamentos ao sistema de microfiltração apresentado na Figura 1. Deste modo, um diagrama esquemático do MBR experimental pode ser visualizado na Figura 2. Então, o MBR apresenta módulo externo, onde o biorreator possui um volume útil de $3 \mathrm{~L}$. O tanque de alimentação (volume útil de $50 \mathrm{~L}$ ), contendo efluente, por meio de bomba peristáltica alimenta o biorreator, o qual é mantido sob regime de mistura completa por meio de um sistema de aeração (pedra porosa e compressor de ar), para manter a biomassa em suspensão bem como fornecer oxigênio aos microrganismos. A bomba de diafragma bombeia o conteúdo do biorreator em direção ao módulo de membranas, o qual separa o fluido em duas correntes: concentrado, que retorna ao 
tanque de aeração; e permeado, o qual é recolhido no tanque de permeado. O módulo de membranas possui as mesmas características apresentadas no item 2.1.

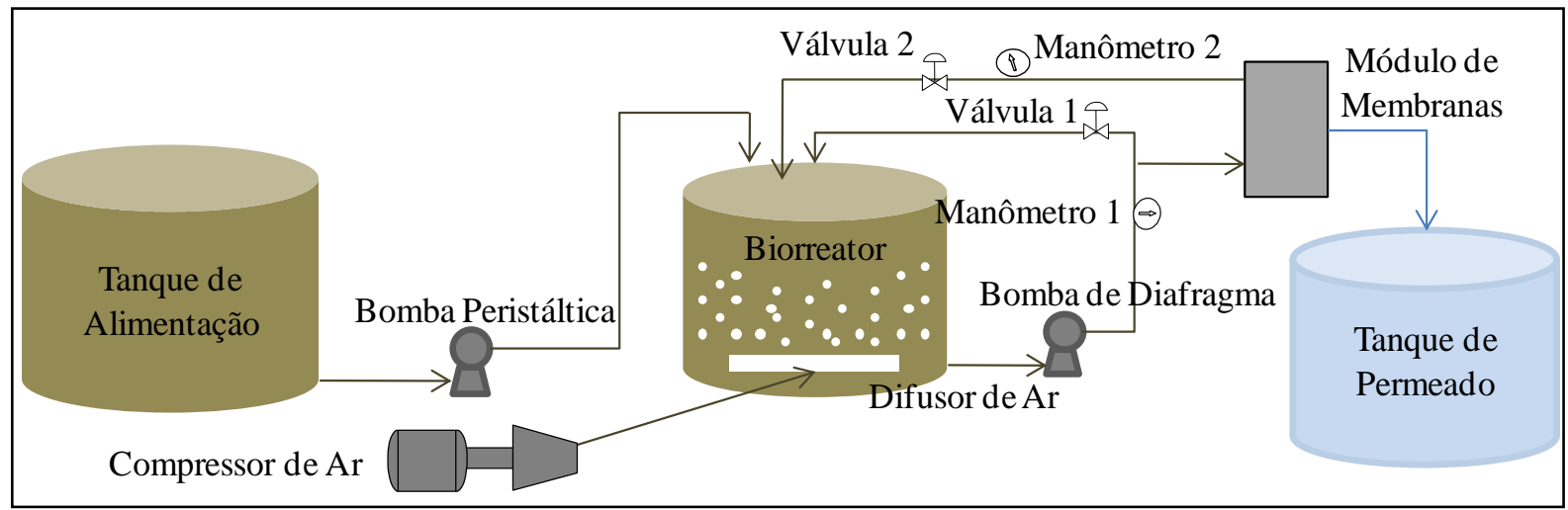

Figura 2 - MBR Experimental.

O MBR foi inoculado com lodo ativado coletado em uma estação de tratamento de efluentes domésticos, sem aclimatação prévia. Os parâmetros SST, PTM e velocidade tangencial adotados, são produto dos ensaios preliminares (item 2.1). Portanto, a concentração inicial foi de $10 \mathrm{~g} / \mathrm{L}$ de SST; a PTM foi mantida constante $\left(0,6 \mathrm{kgf} / \mathrm{cm}^{2}\right)$ e usada a maior velocidade tangencial possível para o sistema, $2 \mathrm{~m} / \mathrm{s}$. O tempo de detenção hidráulica inicial foi de 6,25 $\mathrm{h}$, entretanto, a vazão afluente era diariamente ajustada de acordo com a vazão efluente. Optou-se por trabalhar à temperatura ambiente para simular as condições reais de uma estação de tratamento de efluentes. O experimento perdurou por 8 dias, o sistema foi alimentado com efluente sintético. $\mathrm{O}$ tanque de alimentação ficou completamente fechado e sem agitação.

O efluente sintético (Tabela 5) foi preparado com DQO teórica $=500 \mathrm{mg} \mathrm{O}_{2} / \mathrm{L}$, respeitando a relação ótima DBO:N:P (100:5:1) e complementado com micronutrientes necessários para o adequado metabolismo microbiano (METCALF \& EDDY, 2003). O efluente sintético foi elaborado com estas características a fim de proporcionar uma avaliação da operação do sistema. Apesar de o efluente sintético ter sido elaborado com base na DQO teórica, esta também foi quantificada analiticamente por titulometria (445 $\left.\mathrm{mg} \mathrm{O}_{2} / \mathrm{L}\right)$.

Tabela 5: Reagentes utilizados no efluente sintético

\begin{tabular}{lcc}
\hline \multicolumn{1}{c}{ Nome do Produto } & Fórmula Química & Concentração (mg/L) \\
\hline Etanol 96 GL P. A. & $\mathrm{CH}_{3} \mathrm{CH}_{2} \mathrm{OH}$ & 250,00 \\
Sulfato de Amônio P. A. & $\left(\mathrm{NH}_{4}\right)_{2} \mathrm{SO}_{4}$ & 97,54 \\
Fosfato de Amônio Dibásico P.A. & $\left(\mathrm{NH}_{4}\right)_{2} \mathrm{HPO}_{4}$ & 21,29 \\
Cloreto Férrico P. A. & $\mathrm{FeCl}_{3} \cdot 6 \mathrm{H}_{2} \mathrm{O}$ & 2,42 \\
Cloreto de Cálcio P. A. & $\mathrm{CaCl}_{2} \cdot 2 \mathrm{H}_{2} \mathrm{O}$ & 0,37 \\
Sulfato de Zinco P. A. & $\mathrm{ZnSO}_{4} \cdot 7 \mathrm{H}_{2} \mathrm{O}$ & 0,44 \\
Sulfato de Cobre P. A. & $\mathrm{CuSO}_{4} \cdot 5 \mathrm{H}_{2} \mathrm{O}$ & 0,39 \\
Cloreto de Cobalto P. A. & $\mathrm{CoCl}_{2} \cdot 6 \mathrm{H}_{2} \mathrm{O}$ & 0,42 \\
Cloreto de Potássio P. A. & $\mathrm{KCl}_{2}$ & 0,42 \\
Cloreto de Magnésio P. A. & $\mathrm{MgCl}_{2} \cdot 6 \mathrm{H}_{2} \mathrm{O}$ & 0,42 \\
Sulfato de Manganês P. A. & $\mathrm{MnSO}_{4} \cdot \mathrm{H}_{2} \mathrm{O}$ & 0,42 \\
\hline
\end{tabular}




\section{RESULTADOS E DISCUSSÃO}

\section{ENSAIOS PRELIMINARES}

\section{FLUXO DE PERMEADO REFERENTE À $1^{\text {a }}$ PERMEABILIDADE À ÁGUA}

Após a compactação, cada membrana foi submetida ao ensaio de permeabilidade à água, $1^{\mathrm{a}}$ Perm M1, $1^{\text {a }}$ Perm M2, $1^{\text {a }}$ Perm M3, referentes às membranas 1,2 e 3, respectivamente (Figura 3). Então, através da equação 1 foram determinadas suas respectivas permeabilidades hidráulicas. Desta forma, as membranas 1, 2 e 3 apresentaram as seguintes permeabilidades hidráulicas: 115,158 e $216 \mathrm{~L} / \mathrm{m}^{2}$.h.kgf $/ \mathrm{cm}^{2}$, respectivamente.

Estes resultados mostram que as membranas, pertencentes ao mesmo lote de fabricação, possuem permeabilidades hidráulicas distintas. A permeabilidade hidráulica da M2 é $37 \%$ superior a da M1 e 38\% inferior a da M3. No entanto, ao compararmos as permeabilidades hidráulicas de M1 e M3, a diferença aumenta para $87 \%$.

Não é esperada uma discrepância tão elevada entre membranas do mesmo lote de fabricação, entretanto, este fato pode ser atribuído à variabilidade estrutural do material das membranas, ou seja, o polímero. Segundo Habert, Borges \& Nobrega (2006), regiões cristalinas possuem a estrutura organizada e mais coesa que as regiões amorfas, portanto, a absorção e a difusão de pequenas moléculas são menores. Com base nesta informação, supõe-se que a membrana 3 possui uma estrutura com maior grau de cristalinidade que as membranas 2 e 1 , respectivamente. Além disso, como a área de membrana utilizada nos experimentos é pequena $\left(55 \mathrm{~cm}^{2}\right)$, há uma maior probabilidade de encontrar variabilidade entre as membranas.

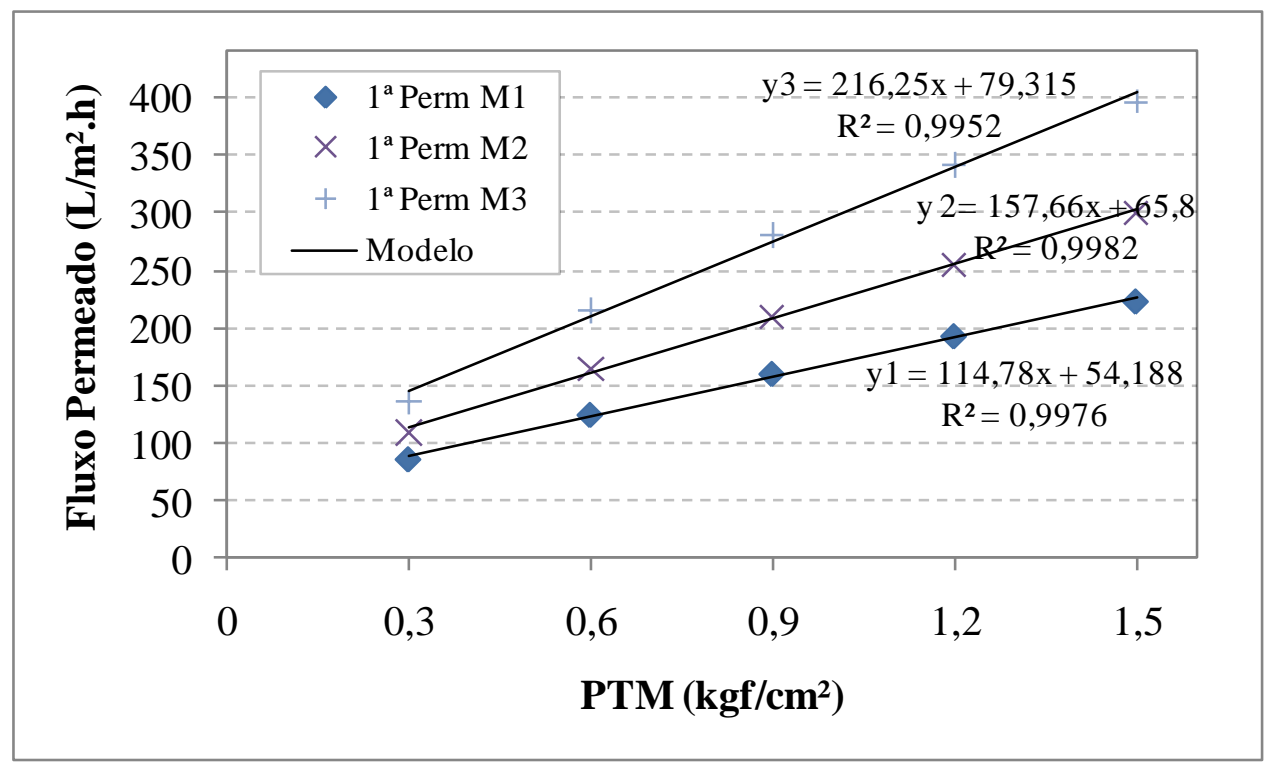

Figura 3 - Permeabilidade hidráulica inicial.

Apesar de constatar que as três membranas apresentaram diferentes permeabilidades hidráulicas, fez-se uma análise estatística para confirmar a descoberta. Então, o fluxo permeado obtido em cada uma das membranas durante os ensaios da $1^{\mathrm{a}}$ permeabilidade à água é apresentado na Tabela 6. 


\begin{tabular}{|c|c|c|c|c|c|c|c|}
\hline \multicolumn{8}{|c|}{ Tabela 6: Resultados do fluxo de permeado para a $1^{\mathrm{a}}$ permeabilidade à água } \\
\hline \multirow{2}{*}{$\begin{array}{c}\text { Fator A } \\
\text { (membrana) }\end{array}$} & \multicolumn{7}{|c|}{ Fator B (pressão) } \\
\hline & $\mathbf{0 , 3}$ & 0,6 & $\mathbf{0 , 9}$ & 1,2 & $\mathbf{1 , 5}$ & Totais & Médias \\
\hline 1 & 86 & 125 & 160 & 193 & 224 & 788 & 158 \\
\hline 2 & 109 & 164 & 210 & 255 & 300 & 1038 & 208 \\
\hline 3 & 136 & 215 & 281 & 342 & 397 & 1371 & 274 \\
\hline Totais & 331 & 504 & 651 & 790 & 921 & 3197 & \\
\hline Médias & 110 & 168 & 217 & 263 & 307 & & \\
\hline
\end{tabular}

Em primeiro momento, avaliando os dados apresentados na Tabela 6 nota-se que as três membranas possuem diferentes fluxos para as mesmas pressões. Entretanto, apenas esta análise visual não permite fazer afirmações, apenas algumas suposições. Portanto, fez-se uma análise estatística, através da análise de variâncias (Tabela 7), para testar a significância desta possível variabilidade.

Tabela 7: ANOVA da $1^{\text {a }}$ permeabilidade à água

\begin{tabular}{c|c|c|c|c|c|c}
\hline ANOVA & SQ & GDL & MQ & F calc & F tab & Significativo \\
\hline A (membrana) & 34218,5 & 2 & 17109,3 & 28,8 & 4,5 & Sim \\
\hline B (pressão) & 71852,4 & 4 & 17963,1 & 30,3 & 3,8 & Sim \\
\hline Erro (AB) & 4744,8 & 8 & 593,1 & & & \\
\hline Total & 110815,7 & 14 & & & & \\
\hline
\end{tabular}

Como já era esperado, em testes de permeabilidade à água, as diferentes pressões apresentaram fluxos distintos. Este fato foi corroborado pela ANOVA (Tabela 7). Entretanto, de acordo com a ANOVA (Tabela 7), também foi verificada diferenças significativas entre membranas pertencentes ao mesmo lote de fabricação. Então, efetuou-se a comparação múltipla das médias para poder avaliar esta variabilidade (Figura 4). Desta forma, ficou comprovado que há diferença de fluxo de permeado entre as três membranas do mesmo lote de fabricação.

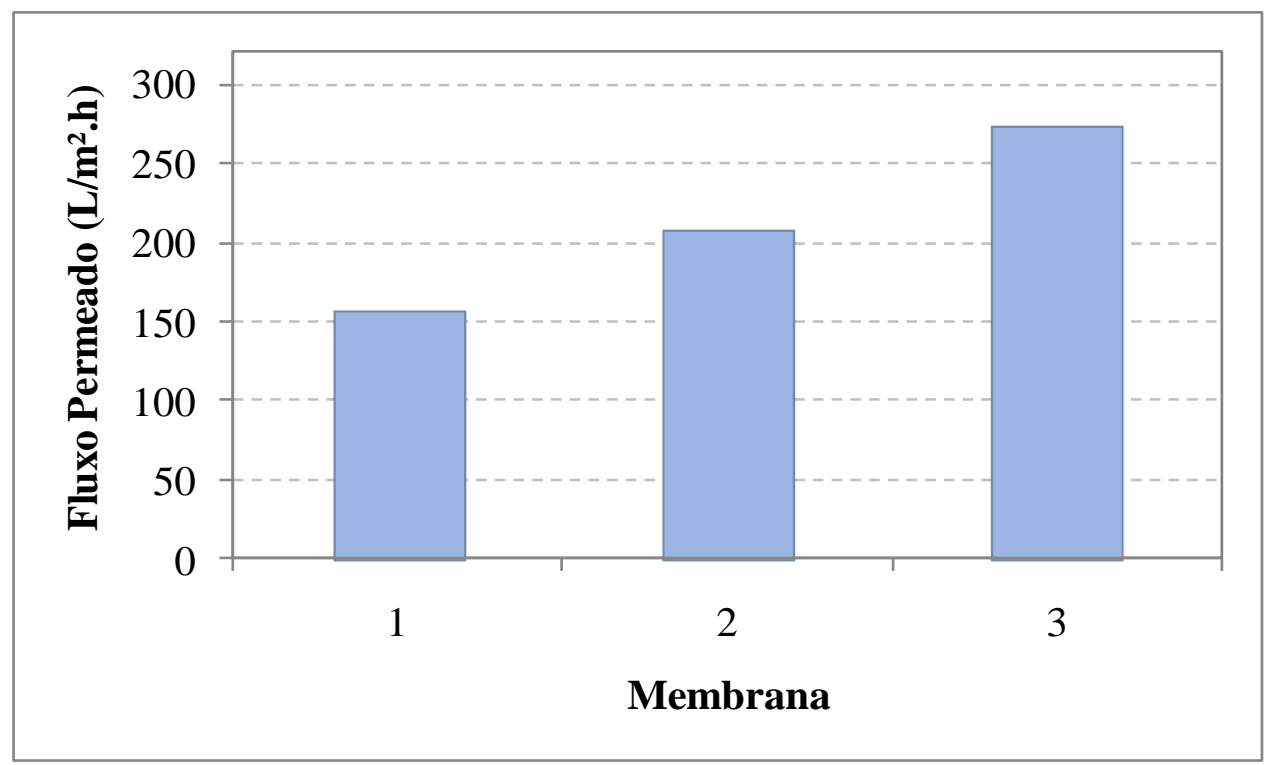

Figura 4 - Fluxo médio de permeado em função das membranas $\left(1^{\mathrm{a}}\right.$ permeabilidade à água). 


\section{FLUXO DE PERMEADO REFERENTE À PERMEABILIDADE AO LODO}

A Tabela 8 mostra os resultados obtidos nos ensaios de permeabilidade ao lodo ativado, os quais foram realizados após a $1^{\mathrm{a}}$ permeabilidade à água.

Tabela 8: Resultados do fluxo de permeado para a permeabilidade ao lodo

\begin{tabular}{c|c|c|c|c|c}
\hline \multirow{2}{*}{ Fator A (concentração) } & \multicolumn{5}{|c}{ Fator B (pressão) } \\
\cline { 2 - 6 } & $\mathbf{0 , 3}$ & $\mathbf{0 , 6}$ & $\mathbf{0 , 9}$ & $\mathbf{1 , 2}$ & $\mathbf{1 , 5}$ \\
\hline $\mathbf{5}(\mathbf{M 1})$ & 75 & 83 & 79 & 73 & 69 \\
\hline $\mathbf{1 0}(\mathbf{M} 2)$ & 65 & 77 & 77 & 71 & 67 \\
\hline $\mathbf{1 5}(\mathbf{M 3})$ & 68 & 78 & 74 & 66 & 63 \\
\hline
\end{tabular}

Em um primeiro momento não foi possível determinar o efeito da concentração de lodo durante o processo de microfiltração, devido às membranas apresentarem diferentes permeabilidades hidráulicas. Entretanto, para possibilitar esta correlação, efetuou-se a padronização da permeabilidade hidráulica das três membranas, o que possibilitou estudar o efeito das diferentes concentrações. Para tanto, estipulou-se que a membrana com maior permeabilidade hidráulica seria escolhida como padrão. Assim, foram atribuídos os pesos 1, 0,73 e 0,53, para as membranas 3, 2 e 1 respectivamente. Então, dividiu-se os valores de fluxo de cada membrana pelos respectivos pesos (Tabela 9).

Tabela 9: Permeabilidade ao lodo com fluxo padronizado

\begin{tabular}{c|c|c|c|c|c|c|c}
\hline \multirow{2}{*}{$\begin{array}{c}\text { Fator A } \\
\text { (concentração) }\end{array}$} & \multicolumn{7}{|c}{ Fator B (pressão) } \\
\cline { 2 - 8 } & $\mathbf{0 , 3}$ & $\mathbf{0 , 6}$ & $\mathbf{0 , 9}$ & $\mathbf{1 , 2}$ & $\mathbf{1 , 5}$ & Totais & Médias \\
\hline $\mathbf{5}$ g/L (M1) & 141 & 156 & 148 & 137 & 130 & 712 & 142 \\
\hline $\mathbf{1 0}$ g/L (M2) & 88 & 105 & 105 & 98 & 92 & 488 & 98 \\
\hline $\mathbf{1 5}$ g/L (M3) & 68 & 78 & 74 & 66 & 63 & 349 & 70 \\
\hline Totais & 297 & 339 & 327 & 301 & 285 & 1549 & \\
\hline Médias & 99 & 113 & 109 & 100 & 95 & & \\
\hline
\end{tabular}

A significância da concentração do lodo e pressão de operação foi testada pela análise das variâncias (Tabela 10).

Tabela 10: ANOVA da permeabilidade ao lodo com fluxo padronizado

\begin{tabular}{c|c|c|c|c|c|c}
\hline ANOVA & SQ & GDL & MQ & F calc & F tab & Significativo \\
\hline A (concentração) & 13417,7 & 2 & 6708,9 & 467,0 & 4,5 & Sim \\
\hline B (pressão) & 668,3 & 4 & 167,1 & 11,6 & 3,8 & Sim \\
\hline Erro (AB) & 114,9 & 8 & 14,4 & & & \\
\hline Total & 14200,9 & 14 & & & & \\
\hline
\end{tabular}

A Figura 5 mostra o fluxo médio de permeado para as três diferentes concentrações de lodo ativado. É possível visualizar que quanto maior a concentração de SST no lodo ativado, menor é o fluxo de permeado. Através do modelo de regressão linear foi calculada a equação que modela este comportamento, e, com uma precisão de $98 \%$, a queda no fluxo de permeado é de aproximadamente $7,5 \mathrm{~L} / \mathrm{m}^{2}$.h para cada aumento de $1 \mathrm{~g} / \mathrm{L}$ na concentração de SST no lodo, para o intervalo estudado. A queda no fluxo foi atribuída exclusivamente ao aumento na concentração de SST no lodo pelo fato de esta ser a única diferença entre os testes, uma vez que todo o lodo usado nos três experimentos provém do mesmo local e da mesma coleta, portanto, com tamanho de floco e idade do lodo semelhantes. 


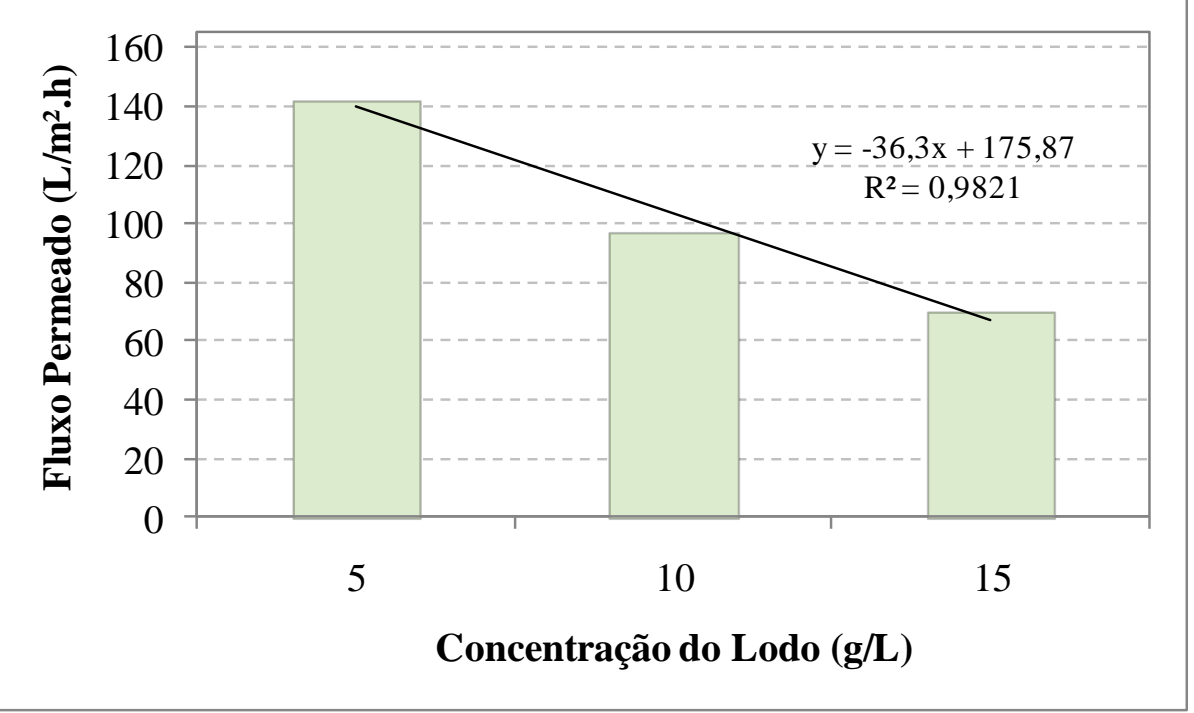

Figura 5 - Fluxo médio de permeado em função da concentração do lodo ativado.

Em relação à PTM de operação, durante a microfiltração do lodo ativado, distinguem-se duas regiões com fluxo praticamente constante (Figura 6). Uma com baixo fluxo de permeado, obtida operando nas pressões de 0,3,1,2 e 1,5 kgf/ $\mathrm{cm}^{2}$ e, outra com alto fluxo, nas pressões de 0,6 e $0,9 \mathrm{kgf} / \mathrm{cm}^{2}$. A partir desta constatação, é apropriado trabalhar com a pressão de 0,6 $\mathrm{kgf} / \mathrm{cm}^{2}$, pois os dois fluxos são estatisticamente semelhantes e, pressões menores consomem menos energia.

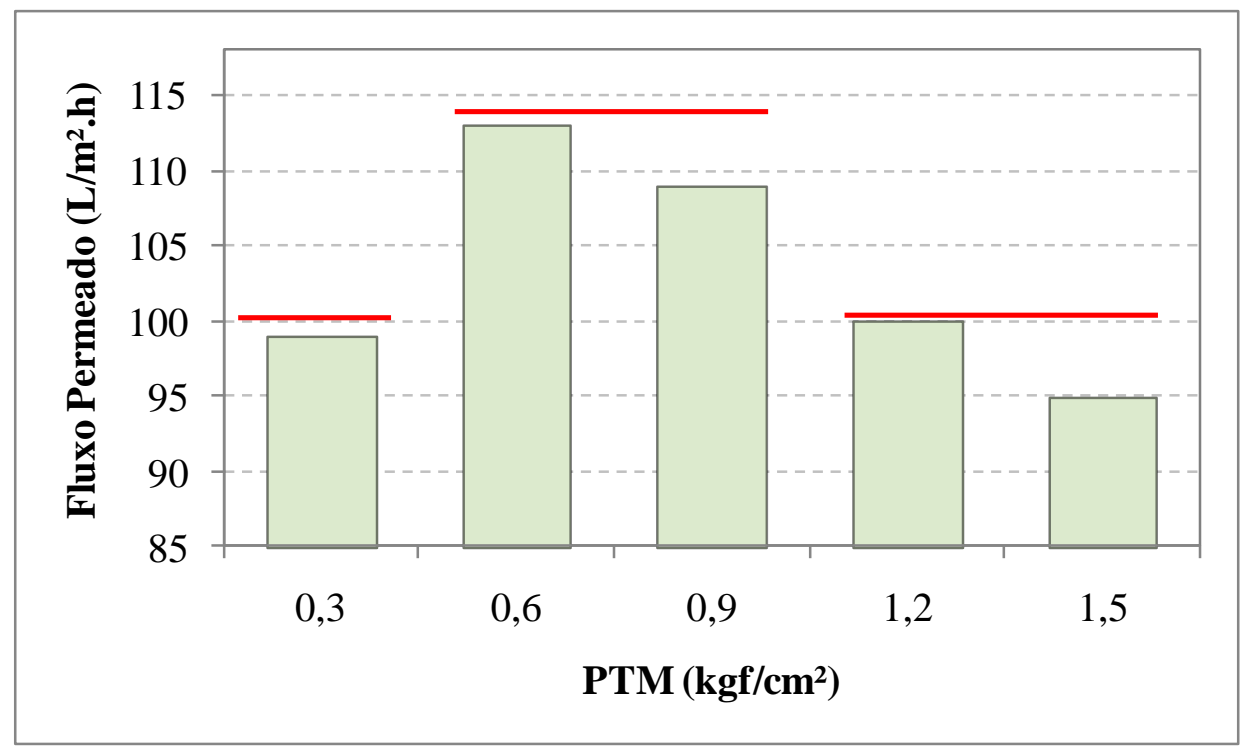

Figura 6 - Fluxo médio de permeado para cada pressão (permeabilidade ao lodo).

\section{FLUXO DE PERMEADO REFERENTE À $2^{\mathrm{a}}$ PERMEABILIDADE À ÁGUA}

Após a permeabilidade ao lodo ativado, cada membrana foi novamente submetida ao ensaio de permeabilidade à água, $2^{\mathrm{a}}$ Perm M1, $2^{\mathrm{a}}$ Perm M2, $2^{\mathrm{a}}$ Perm M3, referentes às membranas 1 , 2 e 3, respectivamente (Figura 7). Desta forma, foram determinadas suas respectivas permeabilidades hidráulicas pós-uso: 36,55 e $50 \mathrm{~L} / \mathrm{m}^{2} . \mathrm{h} \cdot \mathrm{kgf} / \mathrm{cm}^{2}$. 


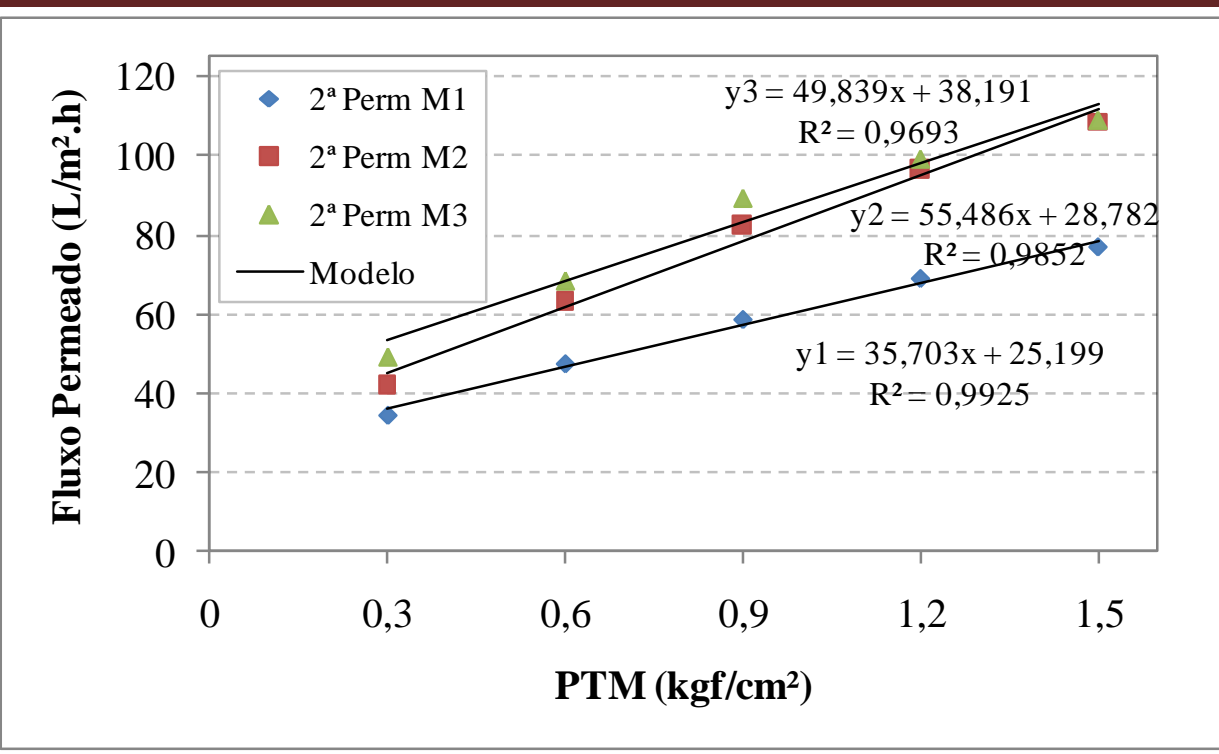

Figura 7 - Permeabilidade hidráulica das membranas pós-uso.

Confrontando os valores das permeabilidades hidráulicas das membranas pós-uso, foi constatado que a membrana 2, que operou com lodo ativado com concentração de $10 \mathrm{~g} / \mathrm{L}$ de SST, passou a ter a maior permeabilidade hidráulica.

Ao comparar as permeabilidades hidráulicas iniciais (Figura 3) com as pós-uso (Figura 7), constata-se que as três membranas apresentaram reduções de 79, 103 e $166 \mathrm{~L} / \mathrm{m}^{2} . \mathrm{h} . \mathrm{kgf} / \mathrm{cm}^{2}$. Estes valores representam 69, 65 e $77 \%$ de redução na permeabilidade hidráulica das membranas 1, 2 e 3, respectivamente. $\mathrm{O}$ fato da membrana 3 ter apresentado maior queda indica que supostamente ela apresentou maior índice de fouling. No entanto, para aumentar a confiabilidade desta afirmação, foi realizada uma análise estatística avaliando os fluxos de permeado da segunda permeabilidade à água (Tabela 11).

Tabela 11: Resultados do fluxo de permeado para a $2^{\mathrm{a}}$ permeabilidade à água

\begin{tabular}{c|c|c|c|c|c|c|c}
\hline \multirow{2}{*}{$\begin{array}{c}\text { Fator A } \\
\text { (membrana) }\end{array}$} & \multicolumn{7}{|c}{ Fator B (pressão) } \\
\cline { 2 - 8 } & $\mathbf{0 , 3}$ & $\mathbf{0 , 6}$ & $\mathbf{0 , 9}$ & $\mathbf{1 , 2}$ & $\mathbf{1 , 5}$ & Totais & Médias \\
\hline $\mathbf{1}$ & 34 & 47 & 59 & 69 & 77 & 286 & 57 \\
\hline $\mathbf{2}$ & 42 & 64 & 83 & 97 & 109 & 395 & 79 \\
\hline $\mathbf{3}$ & 49 & 69 & 89 & 99 & 109 & 415 & 83 \\
\hline Totais & 125 & 180 & 231 & 265 & 295 & 1096 & \\
\hline Médias & 42 & 60 & 77 & 88 & 98 & & \\
\hline
\end{tabular}

Baseando-se nos resultados obtidos na $2^{\mathrm{a}}$ permeabilidade à água, foi feito o teste da ANOVA (Tabela 12).

Tabela 12: ANOVA da $2^{\mathrm{a}}$ permeabilidade à água

\begin{tabular}{c|c|c|c|c|c|c}
\hline ANOVA & SQ & GDL & MQ & F calc & F tab & Significativo \\
\hline A (membrana) & 1928,1 & 2 & 964,1 & 38,6 & 4,5 & Sim \\
\hline B (pressão) & 6130,9 & 4 & 1532,7 & 61,4 & 3,8 & Sim \\
\hline Erro (AB) & 199,9 & 8 & 25,0 & & & \\
\hline Total & 8258,9 & 14 & & & & \\
\hline
\end{tabular}


Através da comparação múltipla de médias (Figura 8) foi constatado que durante a $2^{\mathrm{a}}$ permeabilidade à água, as membranas 2 e 3 apresentaram fluxos médios de permeado estatisticamente semelhantes. Entretanto, no ensaio da $1^{\text {a }}$ permeabilidade à água (Figura 4), a membrana 3 apresentou um fluxo de permeado médio $25 \%$ superior à membrana 2 . Este fato sugere que houve um maior índice de entupimento dos poros, fouling, na membrana 3, a qual trabalhou com a suspensão com maior concentração de SST.

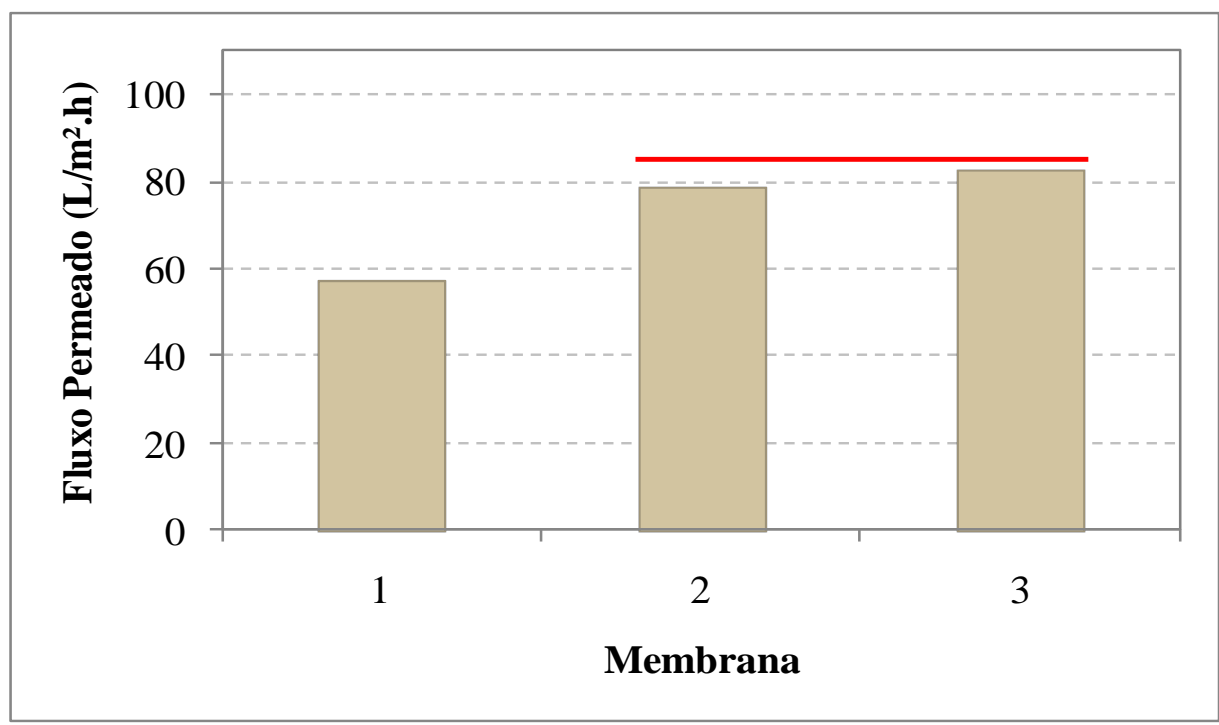

Figura 8 - Fluxo médio de permeado em função das membranas $\left(2^{\mathrm{a}}\right.$ permeabilidade à água).

Ao comparar as médias dos fluxos (Figura 9) realizadas antes e após a filtração do lodo ativado, percebe-se que, em valores absolutos, a membrana 1 apresentou menor queda no fluxo médio de permeado, $100 \mathrm{~L} / \mathrm{m}^{2} . h$, enquanto que as membranas 2 e 3 obtiveram 129 e 191 $\mathrm{L} / \mathrm{m}^{2} . \mathrm{h}$ de queda, respectivamente. Entretanto, em percentual, a membrana 2 teve a menor redução $(62 \%)$ e para as membranas 1 e 3 esta redução foi de 64 e $70 \%$, respectivamente. Portanto, nas condições adotadas nestes ensaios, para diminuir a incidência de fouling, ou seja, o entupimento dos poros da membrana, é recomendável trabalhar com lodo ativado com concentrações de SST iguais ou inferiores a $10 \mathrm{~g} / \mathrm{L}$.

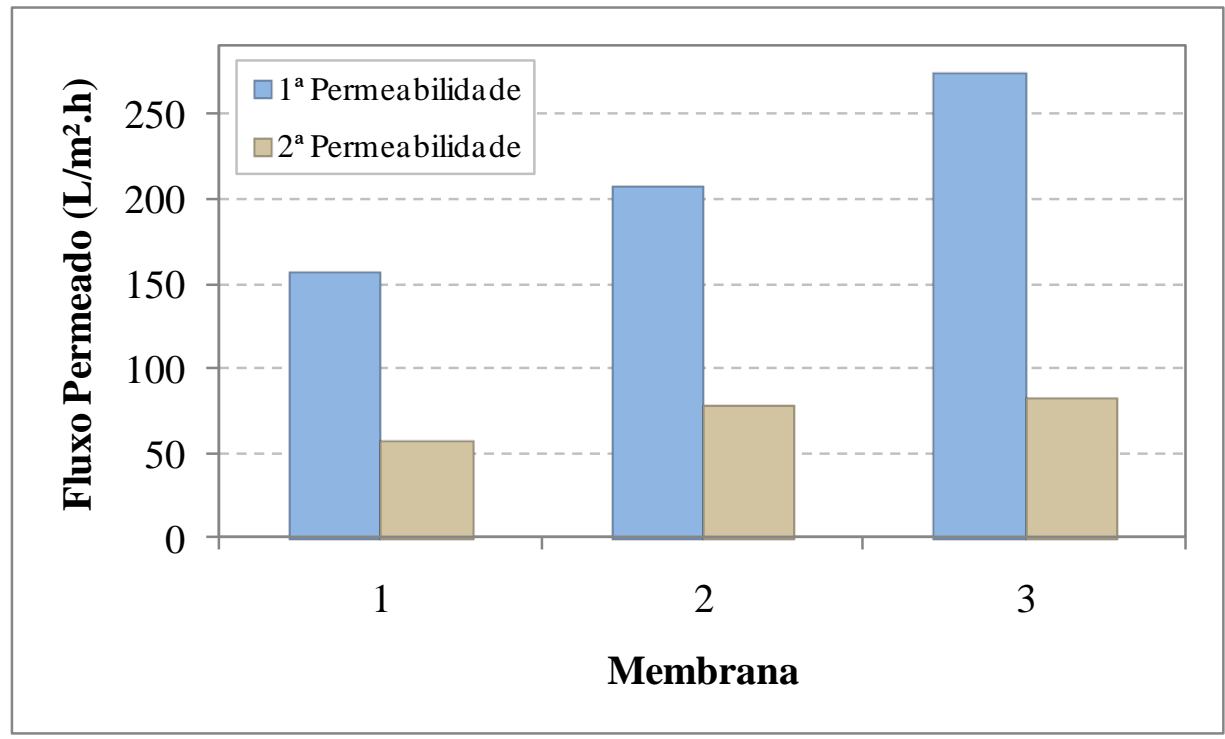

Figura 9 - Fluxo médio dos dois testes de permeabilidade à água em função das membranas. 
Igualmente à $1^{\mathrm{a}}$ permeabilidade à água, a segunda (Figura 10) também apresentou aumento do fluxo permeado com o aumento da pressão. No entanto, este aumento, como já era esperado, foi consideravelmente menor, uma vez que as membranas estavam sob a influência de fouling.

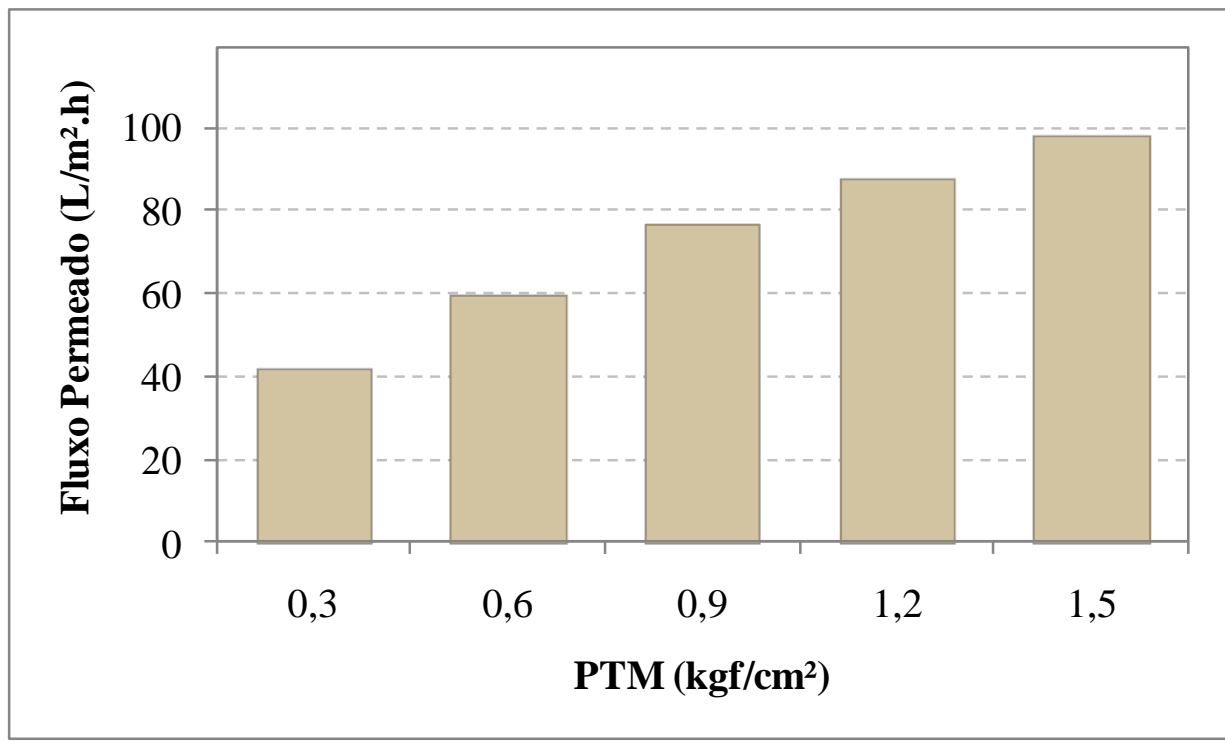

Figura 10 - Fluxo médio de permeado para cada pressão ( $2^{\mathrm{a}}$ permeabilidade à água).

\section{OPERAÇÃO DO MBR}

A operação do MBR começou com fluxo superior a $80 \mathrm{~L} / \mathrm{m}^{2} . h$, contudo foi decaindo ao longo do tempo e tendeu à estabilização por volta de $60 \mathrm{~L} / \mathrm{m}^{2} . h$ ao final da operação (Figura 11). Este patamar de fluxo pode ser considerado alto, ao compararmos com outros trabalhos, uma vez que, trabalhando com MBR externo sob condições operacionais semelhantes e o mesmo período de ensaio, Badani et al. (2005) obtiveram fluxo de $42 \mathrm{~L} / \mathrm{m}^{2}$.h. Além disso, Melin et al. (2006) citam que o fluxo médio para esta configuração de MBR varia entre 25 e $35 \mathrm{~L} / \mathrm{m}^{2} . h$.

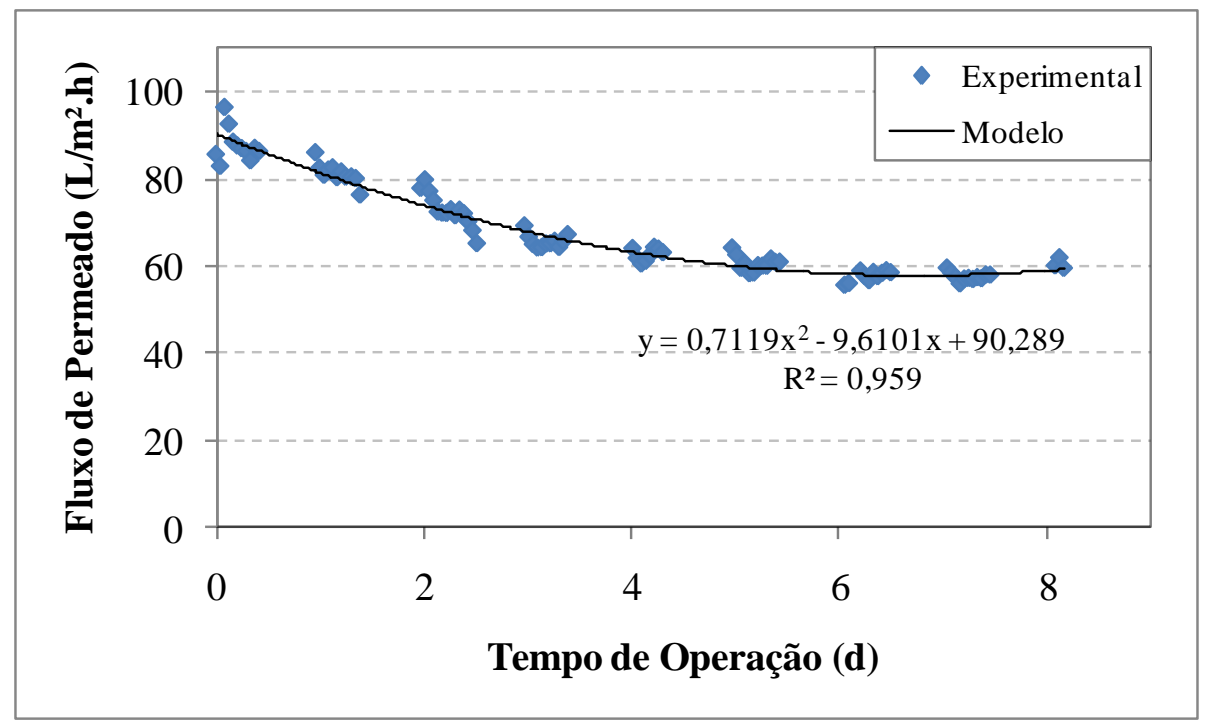

Figura 11 - Fluxo de permeado

Com a finalidade de avaliar a eficiência do tratamento do MBR foi monitorado DQO e turbidez. Durante a operação, o sistema alcançou uma elevada eficiência para remoção de turbidez e DQO, com média superior a $95 \%$ para ambos (Figura 12). Neste caso, pode-se assumir que DQO = DBO, pois o etanol é completamente biodegradável. Estes resultados são 
similares aos obtidos por Provenzi (2005), que também usou etanol como fonte de carbono no efluente sintético.

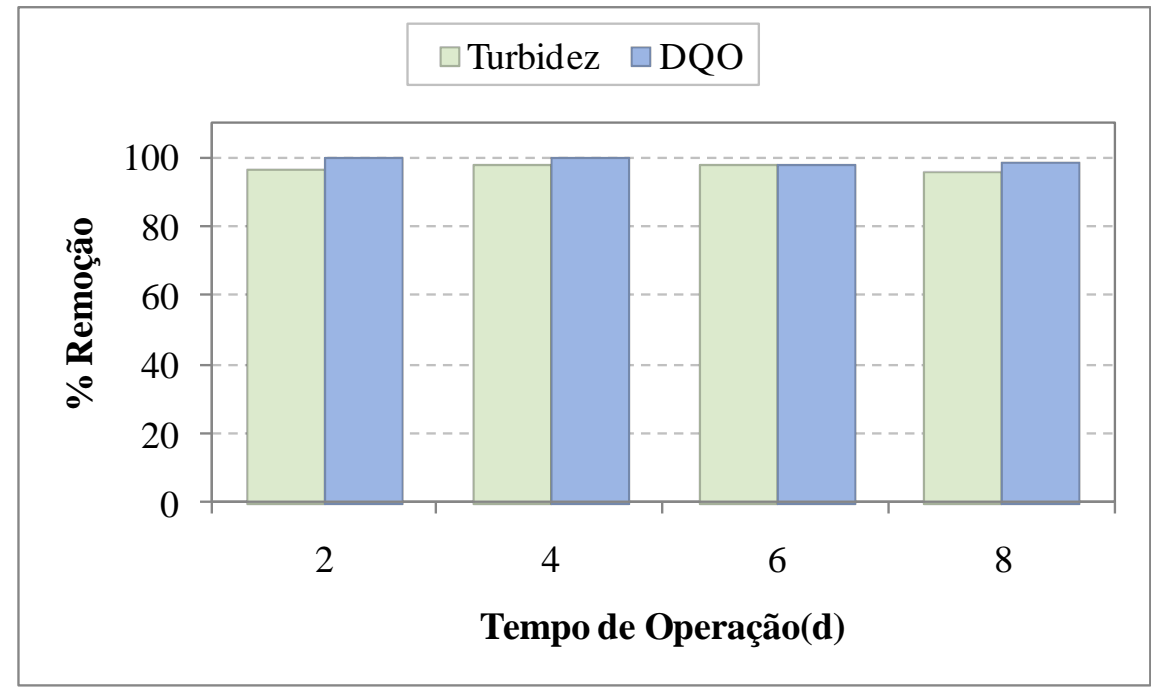

Figura 12 - Eficiência no tratamento com efluente sintético.

Na Figura 13 é apresentada uma foto que possibilita visualizar a aparência das soluções utilizadas no sistema. Nota-se que o efluente sintético tem uma aparência levemente turva, enquanto que o permeado (efluente após o tratamento) possui aparência cristalina, comprovando a efetividade do sistema na remoção de turbidez. Entretanto, a solução a ser filtrada pelas membranas, na realidade é o lodo ativado, que por sua vez tem aparência escura e turva. Portanto, ao comparar o lodo com o permeado, pode ser feita uma avaliação positiva da eficiência das membranas na retenção de sólidos suspensos.

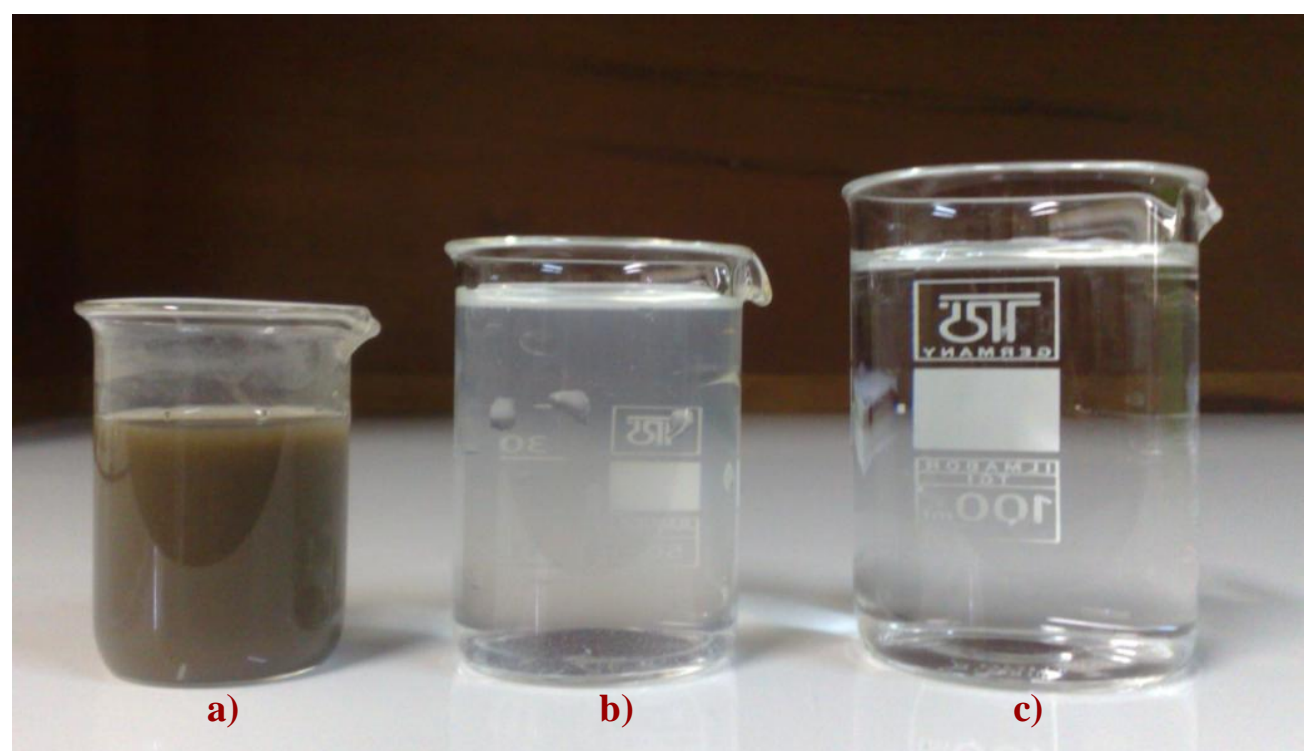

Figura 13 - Aparência das soluções utilizadas. Lodo ativado (a), efluente sintético (b) e permeado (c).

\section{CONCLUSÕES}

A realização do presente trabalho conduziu às seguintes conclusões:

Ensaios preliminares são fundamentais na escolha dos parâmetros de operação, especialmente em PSM, uma vez que cada sistema de filtração possui suas particularidades. Além disso, a 
otimização, antes de iniciar a operação propriamente dita, geralmente proporciona economia de recursos;

Durante os ensaios de avaliação da permeabilidade, pôde-se verificar a influência negativa no fluxo permeado causados pela polarização por concentração e o fouling, possibilitando maior entendimento do comportamento das membranas durante a microfiltração. Através de análises estatísticas foi verificado que membranas do mesmo lote de fabricação apresentam permeabilidades distintas. De acordo com as particularidades do sistema de microfiltração adotados no presente trabalho, a PTM crítica foi de $0,6 \mathrm{kgf} / \mathrm{cm}^{2}$. Portanto, é recomendável trabalhar com pressões iguais ou inferiores à mesma.

Concentrações de lodo ativado mais elevadas provocam maior redução no fluxo de permeado. Os parâmetros ótimos adotados para microfiltração foram $0,6 \mathrm{kgf} / \mathrm{cm}^{2}$ de PTM e lodo ativado com $10 \mathrm{~g} / \mathrm{L}$ de SST.

Após 8 dias de operação, mesmo sem a realização de qualquer procedimento de limpeza da membrana, o MBR manteve-se operando com fluxo elevado, estabilizando em $60 \mathrm{~L} / \mathrm{m}^{2}$.h. E, a eficiência na redução de DQO e turbidez foi superior a 95\%, mostrando-se uma alternativa promissora para o tratamento de efluentes com estas características.

\section{AGRADECIMENTOS}

Os autores agradecem à capes e ao CNPq pelo suporte financeiro e à Ete - São João pelo fornecimento do lodo ativado usado no experimento.

\section{REFERÊNCIAS}

1. BADANI, Z. et al. Treatment of textile waste water by membrane bioreactor and reuse. Desalination, v. 185, n. 1-3, 2005. p. 411-417.

2. GIACOBBO, A. et al. Microfiltração aplicada ao tratamento de efluentes de curtume. In: VII Simpósio Internacional de Qualidade Ambiental. Porto Alegre: ABES, 2010. pp. 1-9.

3. HABERT, A. C.; BORGES, C. P. \& NOBREGA, R. Processos de separação por membranas. Rio de Janeiro : E-papers, 2006. 180 p.

4. LIMPSON, C. \& SHETH, N. J. Statistical Design and Analysis of Engineering Experiments. McGraw-Hill, 1973. 518 p.

5. MAESTRI, R. S. Biorreator à membrana como alternativa para o tratamento de esgotos sanitários e reuso da água. Dissertação (Mestrado em Engenharia Ambiental). Florianópolis : Universidade Federal de Santa Catarina - UFSC, 2007. 101 p.

6. MELIN, T. et al. Membrane bioreactor technology for wastewater treatment and reuse. Desalination, v. 187, n. 1-3, 2006. p. 271-282.

7. MENDRET, J. et al. In situ dynamic characterization of fouling under different pressure conditions during dead-end filtration Compressibility properties of particle cakes. Journal of Membrane Science, v. 333, n. 1-2, 2009. p. 20-29.

8. METCALF \& EDDY. Wastewater Engineering - Treatment and reuse. 4 th ed. Boston : McGraw-Hill, 2003. 1819 p.

9. MONTGOMERY, D. C. Design and Analysis of Experiments. 5th. New York : John Wiley \& Sons, 2001. 684 p. 
10. PROVENZI, G. Biorreator à membrana submersa para tratamento biológico de efluentes: estudos hidrodinâmicos e físico-químicos no controle da colmatação. Tese (Doutorado em Engenharia Ambiental). Florianópolis : Universidade Federal de Santa Catarina - UFSC, 2005. 154 p.

11. RÄDER, A. S. Estudo teórico-experimental do processo de microfiltração de partículas de sílica em suspensão aquosa. Dissertação (Mestrado). Porto Alegre : Universidade Federal do Rio Grande do Sul - UFRGS, 2003. 105 p.

12. RIBEIRO, J. L. D. \& CATEN, C. T. Projeto de Experimentos. Porto Alegre : UFRGS, 2000. 141 p.

13. SCHNEIDER, R. P. \& TSUTIYA, M. T. Membranas filtrantes para o tratamento de água, esgoto e água de reuso. São Paulo : ABES, 2001. 234 p.

14. VIANA, P. Z. Biorreator com membrana aplicado ao tratamento de esgotos domésticos: avaliação do desempenho de módulos de membranas com circulação externa. Dissertação (Mestrado em Engenharia Civil). Rio de Janeiro: COPPE, Universidade Federal do Rio de Janeiro - UFRJ, 2004. 162 p. 